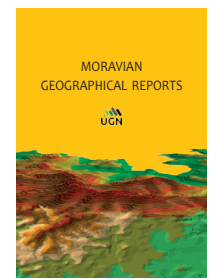

MORAVIAN GEOGRAPHICAL REPORTS

Institute of Geonics, The Czech Academy of Sciences

journal homepage: http://www.geonika.cz/mgr.html

doi: 10.2478/mgr-2019-0010

\title{
Capturing cross-border continuity: The case of the Czech-Polish borderland
}

\author{
Vít PÁSZTO a,b *, Karel MACKŮ a , Jaroslav BURIAN a , Jiří PÁNEK c ${ }^{\text {c Pavel TUČEK a }}$
}

\begin{abstract}
The differences in welfare amongst European countries are especially evident in border regions, and this affects cross-border cooperation and relationships. Due to the historical development of Central and Eastern European countries over the last century, the affected countries are unique "laboratories" for geographical research. This study assesses disparities in socio-economic indicators representing socio-economic phenomena in the Czech-Polish border region, through the analysis of cross-border (spatial) continuity, using quantitative methods (multivariate statistics and socio-economic profiling), GIS analysis and cartographic visualisation. It is demonstrated how such a combination of methods is useful for the comparison and evaluation of the complex socio-economic situations in neighbouring countries. This research project identifies the most suitable common indicators for a proper evaluation of cross-border (spatial) continuity, and it reveals the spatial patterns as reflected by a cluster analysis. The greatest cross-border (spatial) continuity is apparent in the easternmost part of the borderlands, while significant differences on both sides of the border are evident in the very central part of the areas under study. The paper also describes methodological aspects of the research in order to provide a quantitative approach to borderland studies.
\end{abstract}

Keywords: GIScience, socio-economic data, profiling, clustering, border regions, Poland, Czech Republic

Article history: Received 16 January 2019, Accepted 13 June 2019, Published 30 June 2019

\section{Introduction}

According to Bell (2014), the word continuous means 'unbroken' or 'uninterrupted', thus a continuous entity has no 'gaps.' In geography, it is expected that natural phenomena are continuous (in space and time). From the GIScience perspective, Goodchild (1992) claims that "what distinguishes spatial data is the fact that the spatial key is based on two continuous dimensions", meaning that there are no gaps in the Earth's surface (DiBiase, 2014).

Nevertheless, socio-economic phenomena are mainly the product of human activities (Haining, 1993), which are not always continuous in space and time. In GIScience, this kind of phenomena is commonly represented in a non-continuous form, i.e. by using administrative or census units. These discrete objects represent the geographical world as a set of objects with well-defined boundaries in an otherwise "empty space" (Longley et al., 2011). Haining (2003) gives the example of political units (areas) conceptualised as objects - in contrast to, for example, air temperatures, which are conceptualised as fields. In the case of the field representation of geographical phenomena, geo-statistical methods (e.g. kriging) and interpolation methods (e.g. inverse distance weighting - IDW) are ordinarily used to analyse spatial continuity.

Although administrative units seamlessly cover a geographical region, the aggregated socio-economic data within the units may change abruptly from one part to another. Thus, it is not appropriate to apply geo-statistical or interpolation methods to such data to evaluate (spatial) continuity. Haining (2003), however, describes how the values missing from data relating to an area can be obtained using interpolation methods which are more commonly used for naturally continuous data (field representations). The continuity of socio-economic data expressed by administrative or census units (areas) can be evaluated more simply. It is possible to assess (spatial) continuity via a visual analysis of choropleth maps depicting socio-economic data, typically at the interval or ratio level (Haining, 2003;

\footnotetext{
${ }^{a}$ Department of Geoinformatics, Palacký University Olomouc, Czech Republic (*corresponding author: V. Pászto, e-mail: vit.paszto@gmail.com)

${ }^{\mathrm{b}}$ Department of Informatics and Applied Mathematics, Moravian Business College Olomouc, Czech Republic

c Department of Development and Environmental Studies, Palacký University Olomouc, Czech Republic
} 
Robinson et al., 1995; Slocum et al., 2009). To smoothen sharp interval boundaries of attribute data, fuzzy sets and logic can be used, prior to choropleth map-making (Pászto et al., 2015; Woodcock and Gopal, 2000), to evaluate spatial continuity more intuitively. Another way to evaluate the spatial continuity of socio-economic data is to identify units with similar properties through the use of, for example, geographical typology and regionalisation. Moreover, from a quantitative point of view, it is desirable to perform a multivariate statistics and cluster analysis to reveal any common properties of data, especially when using a large number of attributes (e.g. Kaufman and Rousseeuw, 2009; Marek et al., 2015). Clearly, it is important to first establish the purpose or objective of the research, and then to find an appropriate method. Therefore, in the next section there is a brief explanation of the authors' understanding of the continuity of socio-economic data (indicators) as it relates to determining which methods to use.

In the context of cross-border cooperation, it is expected that sub-regions on both sides of a border will share common characteristics and needs. Perkmann (2003) defines (European) cross-border cooperation as a (more or less) institutionalised collaboration between contiguous subnational authorities across national borders, which should generate a cross-border region. In one of his previous works (Perkmann, 2002), this author mentions that for Western European countries cross-border cooperation has been strongly institutionalised and attributed to long-lasting activities. The cross-border region is characterised by homogeneous features and functional interdependencies, because otherwise there is no need for cross-border cooperation (CoE, 1979). Moreover, Jaschitz (2013) emphasises that for cross-border areas there is a need for cross-border cooperation among local actors, especially while the border plays the role of a contact zone.

Many contributions dealing with cross-border cooperation have been presented worldwide. Some have concentrated on the role of the borders themselves (e.g. Anderson and Wever, 2003; Diener and Hagen, 2012; Guichonnet and Raffestin, 1974; Martinez, 1994; Minghi, 1963; Prescott, 1965; Van Houtum, 1998), classifying them according to a specific function (conceptual, thematic, process-based), origin (natural or artificial), frontier-type (political, cultural, mental), or as cross-border flows. A very large number of papers, reports and studies about borderland regions, cross-border cooperation, cross-border interactions and related topics are available from various institutions (e.g. Association of Borderland Studies, Association of European Border Regions, Centre for Borders Research at Durham University, Centre for Cross Border Studies), transnational program documents (e.g. European Commission, Central European Free Trade Agreement, North American Free Trade Agreement, Mercosur), and scientific journals (especially the Journal of Borderland Studies, and other geographical and policy-oriented journals).

Nevertheless, in the case of Central and Eastern European countries (including the Czech Republic and Poland), the European Commission (AEBR and the European Commission, 2000) states that approaches to cross-border cooperation started to emerge after 1989 with the opening of the borders. In this region it has been necessary to cooperate "in order to offset the geographical disadvantages of border areas and the huge disparities in incomes and infrastructure... amongst these countries themselves" (AEBR and the European Commission, 2000, p. 7). Within this context, the permeability of the borders creates great potential for further local or regional socioeconomic development. On the other hand, there is an emerging demand for the protection of external borders (a border as a barrier or filter zone), especially regarding the recent immigration crisis in Europe (e.g. Carrera et al., 2015; Havlíček, Jeřábek and Dokoupil, 2018).

In the case of the Czech and Polish cross-border cooperation, these efforts were accelerated by EU programs (e.g. Phare and INTERREG), but disparities are still present. Studies on Czech-Polish cross-border cooperation were mainly conducted by Czech and Polish researchers, usually with a focus on one specific geographical theme (Heffner, 1998; Szczyrba, 2005), sub-region (Mintálová and Ptáček, 2012; Runge, 2003), and/or higher level administrative units (ČSÚ, 2005; Dołzbłasz, 2013; Kladivo et al., 2012). Such studies also demonstrated limited use of GIScience methods.

In this paper, the authors deal with socio-economic indicators (using the local administrative units, level 2 - LAU2) which reflect the social, demographic and economic situation in the Czech-Polish border regions. The overall objective of the paper is to capture cross-border continuity (or discontinuity) of socio-economic phenomena (represented by respective indicators) in the Czech-Polish border regions using a combination of methods. This objective is partitioned into a leading research question is: Is the cross-border continuity of socio-economic phenomena even visible in the available data? Which (non-)spatial tools would be best utilised to reveal a (spatial) pattern of the cross-border continuity? How can the resulting analysis from these tools be interpreted, and what are the most (dis) continuous borderlands?

\section{Cross-border continuity of socio-economic indicators - a concept}

The following concept of cross-border (spatial) continuity of socio-economic indicators is based on a typology of borderland regions and models of borderland interactions. Generally, borderlands are areas on the fringe of a national territory (Tykkyläinen, 2009). As such, these rather peripheral regions exhibit diverse functions according to the specific inter-relations with their crossborder neighbours. Strassoldo-Graffenberg (1974) defined borderland regions in relation to their permeability into four types: closed borderland regions; one-way opened borderland regions; partially opened borderland regions (bridge system); and fully opened borderland regions (system of contact territories). These different types of borderlands imply different border effects. Considering the border effect, Martinez (1994) proposed four models of borderland interaction: alienated borderlands; co-existing borderlands; interdependent borderlands; and integrated borderlands. Various aspects of types of border regions with detailed literature reviews were discussed in Dokoupil and Havlíček (2002), and they suggested that continuous border relations are only present where there are open borders. In the context of types and models of the borderlands mentioned above, the continuity of human and economic activities requires a system of contact territories and interdependent or even integrated borderlands. It is not a trivial task, however, to evaluate the integration of borderlands, and this can involve combinations of qualitative and quantitative methods. With respect to the historical background and 
current situation of the study area in this paper, i.e. the Czech-Polish borderland, a concept of cross-border (spatial) continuity of socio-economic indicators is introduced. In this concept, the authors use rigorous quantitative approaches, supplemented with visual analytics and expert knowledge (for more details, see Section 3.4 below).

From our perspective, cross-border (spatial) continuity can be described as: the smoothness and/or trend in which the change in the indicators' values occurs in the direction from the inner part of country: from country A through its borderlands, across the border and to the inner part of country B. The authors characterise the most common types of cross-border (spatial) continuity based on trend curves, as follows:

- constant - this is the ideal type of continuity (Fig. 1a);

- progressive and regressive - the values gradually increase from country A to country $B$, and vice versa, i.e. the values gradually decrease from country A to country B (Fig. 1b);

- ridge - high values around a border with a gradual decrease towards the inner parts of both borderland regions (Fig. 1c);

- valley - opposite to the ridge type, i.e. low values around a border can be identified, with the increasing trend towards the inner parts of both borderland regions (Fig. 1d);

- oscillating - the phenomena do not show any significant trend; neither continuity nor discontinuity can be identified (Fig. 1e) and

- abrupt - this type is characteristic of distinct (spatial) discontinuity (Fig. 1f).

From a geospatial perspective, this concept could be used for line transitions (in the case of LAU2 units, these are individual municipalities along the studied axis/direction), or areal transitions (the whole borderland region is evaluated). The concept is most suitable for the interpretation of socio-economic profiling analyses. It could however also be easily applied to the results from cartographic visualisation (choropleth maps) and cluster analysis. In combination with the methods used in this paper (Section 3.4), it helps to assess the overall picture of the cross-border (spatial) continuity of socio-economic indicators.

\section{Material and methods}

\subsection{Historical background}

The Czechoslovakian borders newly established after World War I did not correspond to the ethnic composition of the population (see Fig. 2). Except for its eastern part, the Czech borderland is often called Sudetenland. This area is characterised by various historical developments that have played a significant role in shaping it into its current form. Sudetenland resulted from the Munich Agreement in 1938, and its status as a German Third Reich land continued until the end of World War II. In the dramatic post-war period, that part of the population with German nationality was forced to leave the region. The displaced German population was quickly replaced with new settlers and a new industrialised area with a high migration rate was created. On the other hand, Poland claimed the Teschen region (the north-east of Czechoslovakia), and in August 1945, nearly 700,000 new Polish settlers were transferred to the region. At the same time, the Czechoslovaks were told that if they did not take Polish nationality, they would be expelled from the area. This led to the expulsion of 21,000 Czechs from the Polish part of the border region. Through this act, Poland annexed original territories from Czechoslovakia. The disputes did not cease however until 1947, when a Treaty of Friendship and Mutual Assistance was concluded between Czechoslovakia and Poland. In the 1950s, the Treaty between Czechoslovakia and the People's Republic of Poland on the definitive demarcation of state borders was signed, and this resulted in minor border adjustments in the form of Czechoslovak territorial gains. The present form of the state border was defined by the Treaty between the Czech Republic and the Republic of Poland on Common State Boundaries from 1996. Historical events influenced the border region, particularly the geo-demographic and socioeconomic situation, which makes the region particularly interesting from a research perspective.

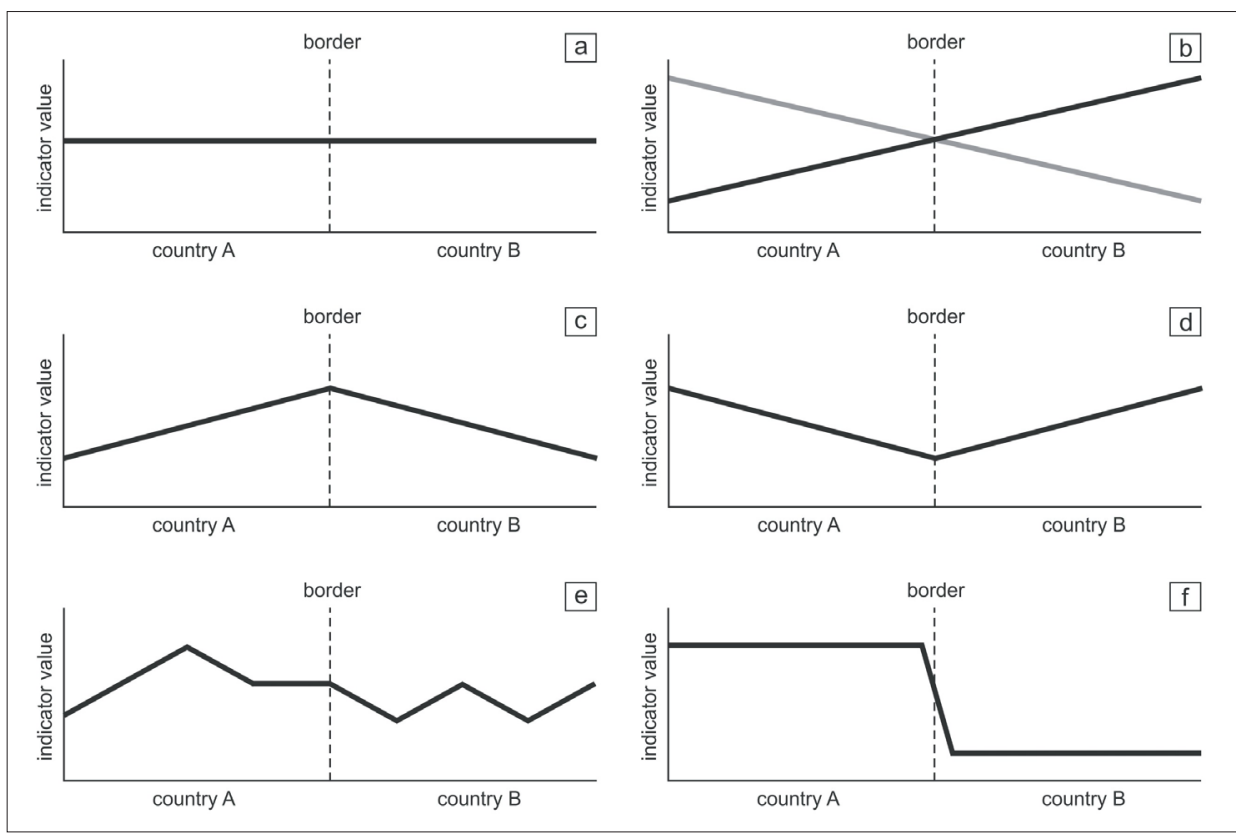

Fig. 1: Main types of cross-border (spatial) continuity of socio-economic indicators Source: authors' visualisation 


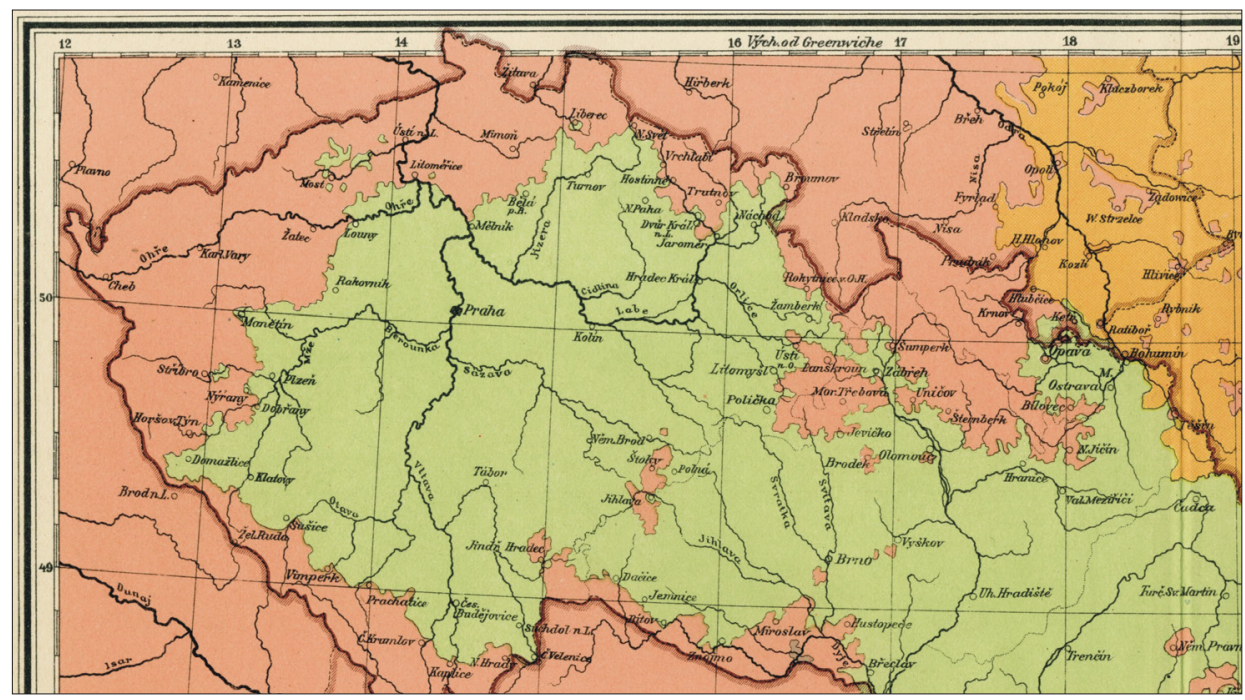

Fig. 2: Map segment of ethnicities in Czechoslovakia and neighbouring countries in 1930 (Colours: red represents Germans; green, Czechoslovaks; and orange, Poles. German ethnicity in the Czech territory closely corresponds with the Sudetenland borders established in 1938). Source: Brunclik and Machát (1930)

For more information, a comprehensive overview of the German influence on Poland and the Czech Republic is given in an historical context by Cordell and Wolff (2005). For instance, these authors mention that German ethnicity plays a minor role in the Czech Republic in comparison with Poland, where the ethnic has been reconstituted as a conscious entity. Further in-depth research about the former Sudetenland and the impact and consequences of World War II on the Czechoslovak borderlands is provided by Glassheim (2016), who touches on topics such as expelling German ethnic persons and resettlement programs, as well as environmental and health issues in the borderlands.

\subsection{Study area}

The region in this study is depicted in Figure 3 and was selected as in Kladivo et al. (2012). The delimitation of the study area follows administrative divisions on both sides of the border (in general, these administrative units are in size between LAU1 and LAU2). These medium-detailed administrative units have relatively similar size in terms of population, which is very important regarding socioeconomic analyses. Subsequently, these units have been replaced by the most detailed level (municipalities, i.e. LAU2 units) to obtain the highest spatial resolution.

The overall area of the region is approximately 20,000 square kilometres (roughly the same size as Slovenia) and it is divided by the border into Czech and Polish parts (with approximately the same size). Both regions are composed of the smallest local administrative units (i.e. LAU2) as defined by Eurostat (2015) for statistical purposes. It is worth noting that the unequal average size of individual territorial units on the Polish and Czech side causes different spatial fragmentation. It is apparent at first glance from the number of municipalities in both states - in Poland,

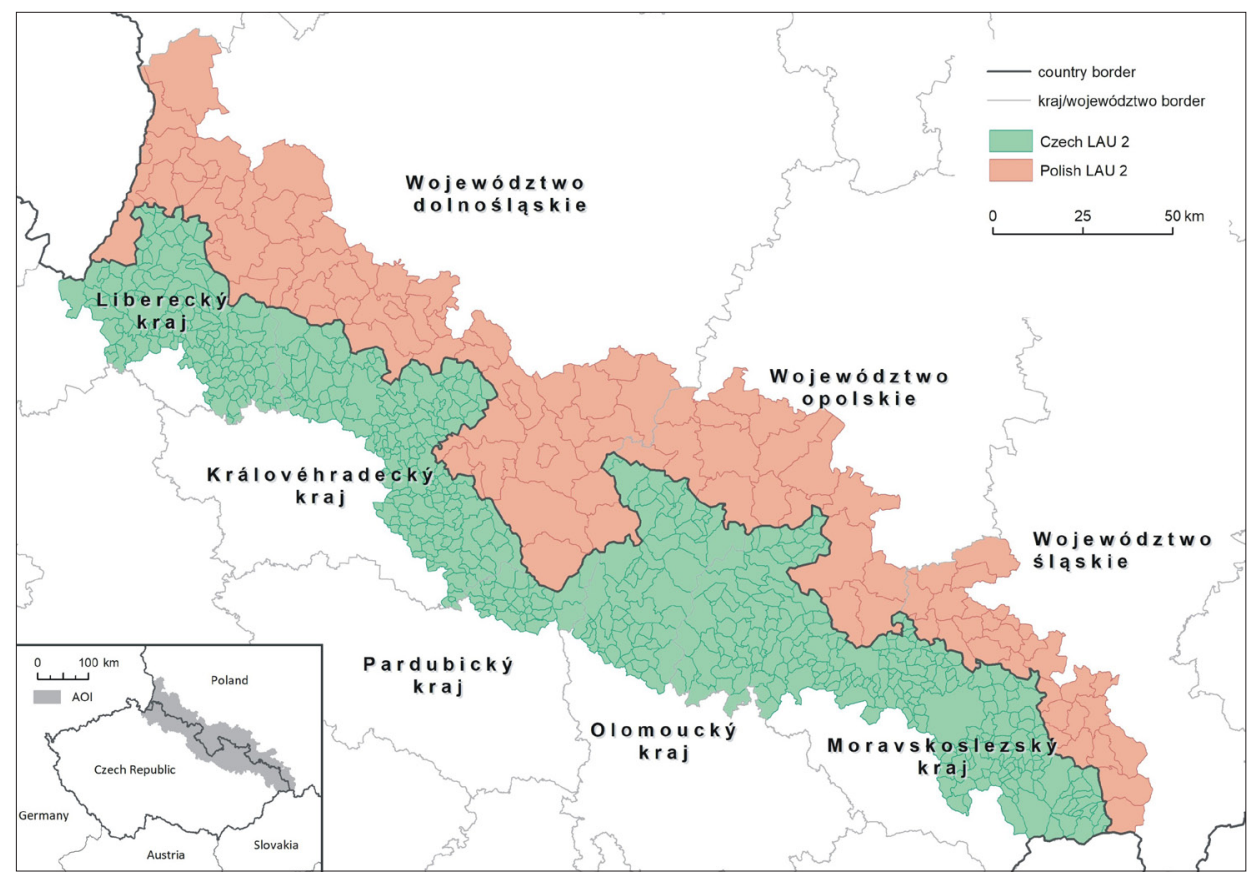

Fig. 3 Study area of the Czech-Polish borderlands

Source: authors' elaboration 
109 municipalities (gminy) were selected and in the Czech Republic, 604 municipalities (obce). This problem is present, however, when comparing most European countries, and other administrative divisions at this or a finer level are simply not available.

\subsection{Data}

Attribute data were acquired for the LAU2 units from national statistical offices: the Czech Statistical Office and the Central Statistical Office of Poland, with the reference date 2014. Although both statistical offices have a large amount of socio-economic indicators available to download, not all are available at the level of LAU2 for both countries. Therefore, only the relevant indicators available for both countries for LAU2 were included in this study in order to evaluate their continuity (Tab. 1). Geographically, there are 109 LAU2 on the Polish side and 604 units on the Czech side. For every unit, 43 indicators were obtained but not all were used in further analyses (see below for more details, Section 3.4.3). Geographical data were obtained from the Polish Office of geodesy and cartography (CODGiK) database, and from the ArcCR $\AA 500$ database provided by the Czech company ARCDATA PRAHA and the State Administration of Land Surveying and Cadastre (ČÚZK).

\subsection{Evaluation of cross-border continuity}

In order to evaluate the continuity of selected socioeconomic indicators, three methods were used:

1. cartographic visualisation as a proxy for visual analytics was used - in total, 26 choropleth maps were made to depict the (dis)continuity of each individual indicator;
2. the socio-economic profiles of socio-economic indicator values in LAU2 following cross-border development axes were calculated - this approach is inspired by topographic profiling, usually used in physical geography. Socio-economic profiling is based on the theoretical concepts introduced in Section 2, above;

3. statistical analyses were carried out in order to: (a) reduce the dimensions of attribute data with the use of Pearson's correlation; (b) find groups of similar LAU2 areas (according to socio-economic indicators) by hierarchical clustering using Ward's method.

For the statistical analyses, IBM SPSS Statistics and RStudio software were used. Further analyses were carried out in Esri ArcMap from the ArcGIS Desktop family. Additionally, a special toolbox in Esri ArcMap was prepared by the authors for more comprehensible visualisation and analysis of clustering results. Key features of the toolbox are: (a) user- defined threshold for LAU2 area size; (b) user-defined LAU2 distance from the borderline; and (c) automatic calculation of basic statistics of socio-economic indicators in particular LAU2 areas.

\subsubsection{Cartographic visualisation}

The choropleth method is one of the most commonly used cartographic tools for displaying the intensity of phenomena in a monitored area. The intensity is graphically expressed by colour or raster (patternfilling). Thechoropleth maprepresents relative values in order to compare the various spatial units. An important issue is the creation of the interval scale, which also influences the correct interpretation of a map's content. Usually, it is recommended to use 4-10 intervals,

\begin{tabular}{llll}
\hline Abbreviation / Indicator & \multicolumn{2}{l}{ Abbreviation / Indicator } \\
\hline P & Population, total & AI & Ageing index \\
P14 & Population ages $0-14$ & JS & Job seekers \\
P64 & Population ages 15-64 & ANFC & Absolute number of completed flats \\
P+ & Population ages 65+ & AAGR & Area of agricultural land \\
AA & Average age & ABUA & Built-up area \\
M & Population, male & PD & Population density \\
W & Population, female & MI & Masculinity index \\
FI & Femininity index & CBR & Crude birth rate \\
B & Births & CMR & Crude mortality rate \\
D & Deaths & RNI & Rate of natural increase \\
NI & Natural population increase & NMR & Net migration rate \\
I & Immigrants & RTG & Rate of total population growth \\
E & Emigrants & CMR & Crude marriage rate \\
MB & Migration balance & IMR & Infant mortality rate \\
TG & Total growth & DR & Dependency ratio \\
MA & Marriages & EAI & Economic activity index \\
D & Divorces & UR & Unemployment rate \\
CDR & Crude divorce rate & NFC & Number of completed flats (per 1,000 inhabit.) \\
A & Abortions & AGR & Proportion of agricultural land \\
CAR & Crude abortion rate & BUA & Built-up area ratio \\
DI & Dependency ratio I & CES & Coefficient of ecological stability \\
DII & Dependency ratio II & \\
\hline & & & \\
\hline
\end{tabular}

Tab. 1: Complete list of socio-economic indicators obtained for the study (Note: Attributes in bold were selected for final analysis) 
but it is important to note that a small, as well as a large, number of intervals, degrade the map. In the case of a large number, the map is mostly not easily interpreted, and, in the opposite case, it erases the differences between the individual units. In this research project, four and five intervals using Jenks' 'natural breaks' method have been chosen to minimise variability within intervals (by minimising average deviation from the interval mean) and to maximise its diversity among them (by maximising each interval deviation from the means of the other intervals) (Jenks, 1967). This approach reflects natural groupings inherent in the geographical data and is one of the most commonly used in the geosciences (Dvorský et al., 2013). The study area (area of interest: AOI) was evaluated through visual analysis and it was possible to create the first statements about the behaviour of the observed phenomena in the Czech-Polish borderlands (see Fig. 4).

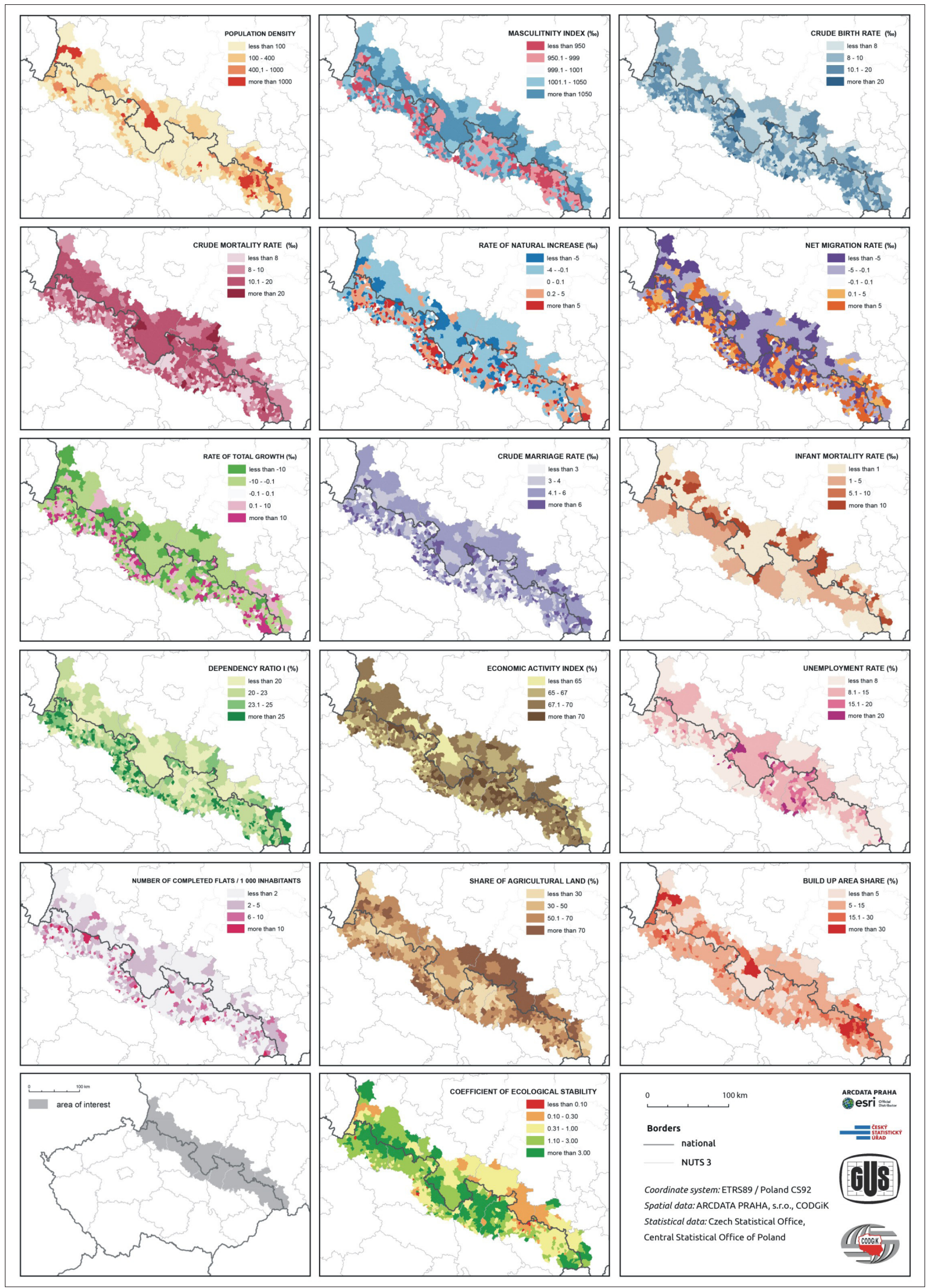

Fig. 4: Selected indicators visualised on choropleth maps. Source: authors' calculations and visualisation 
Using choropleth maps with indicators classified into four or five classes, it is possible to acquire general knowledge about cross-border (dis)continuity patterns. Visually, the greatest spatial continuity appears to occur in the case of population density. Since most of the borderlands in both countries could be treated as peripheral regions, and due to the mountainous character of the landscape along the border, there is evident cross-border continuity, mainly of low values. There is a clear exception in the most eastern part of the studied area, which is situated in lowlands and is historically a centre of heavy industry connected with mining. Therefore, a considerable number of towns and cities is located in this area, which has a direct influence on the indicator of population density. Another example of cross-border spatial continuity is the indicator of unemployment rate. Higher values of the index in the central part of the study area are affected by the mountainous terrain, and the consequent low economic performance due to industry not being subsidised by post-socialist governments. A relatively high degree of spatial continuity can also be seen in the economic activity index.

A good example of cross-border spatial discontinuity (obviously with several local exceptions) is manifested by the masculinity index, the rate of total population growth, the dependency ratio and the rate of natural increase. Given the female prevalence in the population on the Czech side, according to the masculinity index, the crude birth rate is also higher, which results in a certain level of discontinuity. A combination of local cross-border spatial continuity and discontinuity can be found in the share of agricultural land and the coefficient of ecological stability. It is logical and evident that these two indicators are complementary in almost all the study area. Again, looking at the central part, cross-border spatial discontinuity is clear with a relatively high proportion of agricultural area on the Polish side, and a low proportion on the Czech side. The rest of the study area is more cross-border spatially continuous, as regards this indicator. Analogically, the coefficient of ecological stability is the reverse of the proportion of agricultural area.

The remaining indicators evince cross-border spatial (dis) continuity locally and should be interpreted with this fact in mind. In general, it is important to take the local context into consideration when interpreting all the maps, but the spatial pattern of the indicators mentioned above is the most apparent, even on a regional scale. Moreover, it is desirable to generalise the visual analysis by omitting small LAU2 units that disrupt map reading. Due to the local heterogeneity of indicator values, it is impossible to find perfect (dis) continuity, but at the same time it is feasible to uncover homogeneous spatial patterns in cross-border spatial (dis) continuity. The setting of interval ranges also affects the overall visual impression gained from choropleth maps. As mentioned earlier, the authors chose Jenks' methods for data classification into four or five intervals, but interval boundaries were then justified for each choropleth map in order to meet cartographic rules (rounded intervals in this case). Yet, every classification simplifies the information, therefore even slight modifications to interval boundaries may cause significant changes in the final appearance of the map.

\subsubsection{Socio-economic profiles}

Socio-economic profiling offers a different point of view of the (dis)continuity. It is possible to evaluate an increase (or a decrease) in the continuity of socio-economic indicators in one direction across the border. This method is inspired by the elevation (longitudinal) profile method, but here it shows the values of the studied phenomena instead of the altitude between points A and B. In this project, socio-economic profiles were constructed in directions that follow development axes in the area of interest. Four development axes between the Czech Republic and Poland were drawn based on the Czech and Visegrad groups' strategic documents (ISD et al., 2014; MRD and ISD, 2015). Two additional axes were defined by the authors to cover the remaining parts of the study area.

Axes 1 and 2 form two major European routes from Poland to the Czech Republic. Axis 1 crosses the industrial city of Katowice and continues through Ostrava towards Přerov and Brno. Axis 2 leads from Wrocław to Praha (Prague) via the towns of Trutnov and Hradec Králové. Axis 3 was defined with respect to the important Czech development area around Liberec, heading to Praha (Prague) on the Czech side, and to Legnica in Poland. Axis 4 is a planned development axis and was recently defined in Czech strategic documents.

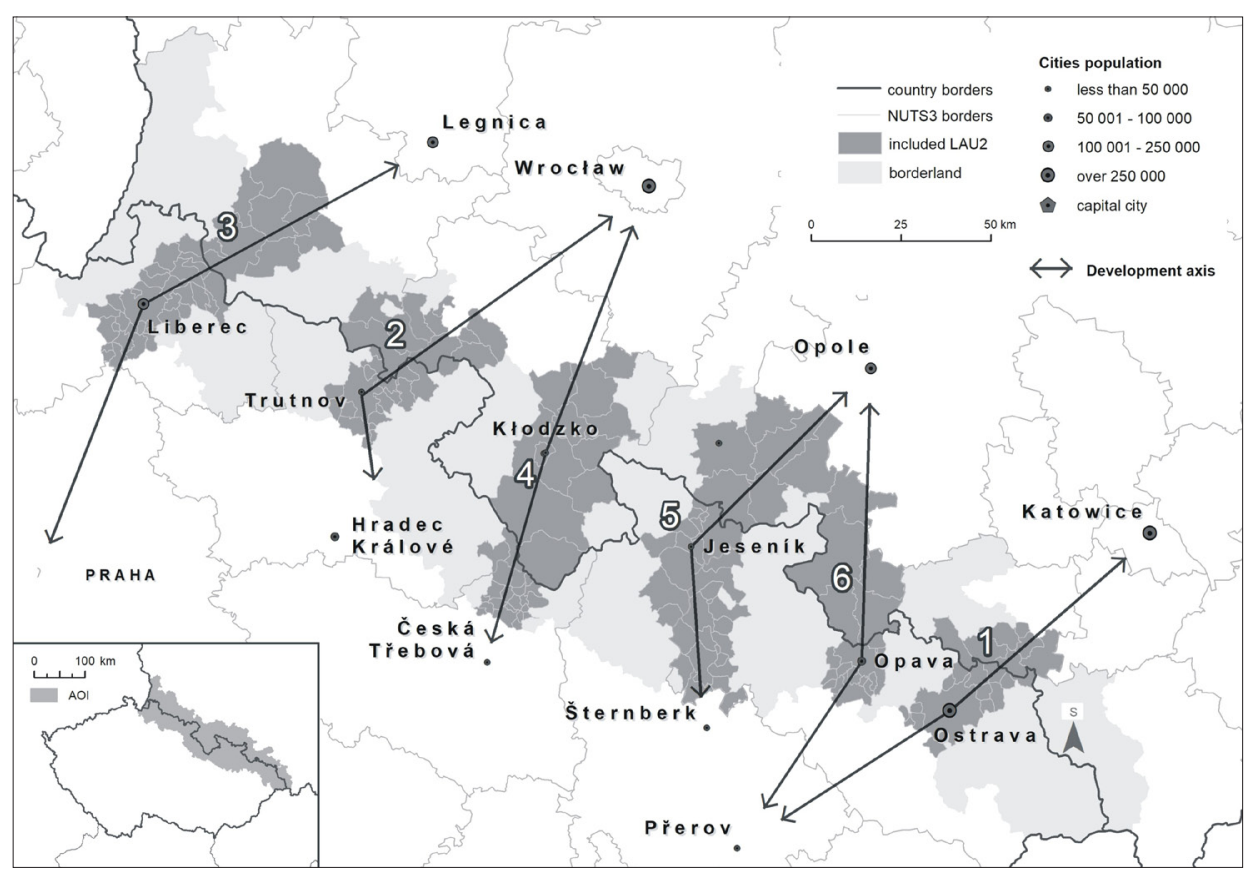

Fig. 5: Development axes in the Czech-Polish borderlands. Source: authors' calculations and visualisation 
It leads from Wrocław, via Kłodzko and continues to the Czech town of Česká Třebová. Axes 5 and 6 were created by the authors, who noted the absence of any significant infrastructure links, rail or road. Therefore, they are not strictly development axes but selected "axes of interest". For simplicity, the authors also refer to the latter as development axes. All development axes are depicted in Figure 5.

For each development axis, a selection of sixteen socioeconomic indicators was profiled in order to evaluate cross-border (dis)continuity in view of the theoretical concept described in Section 2, above. It is possible to comprehensively interpret individual socio-economic profiles within a development axis from one diagram, or to focus on individual indicators across all development axes (see Table 2). In the first case, a graph matrix with all indicators displayed together was prepared. An example of such a matrix for development axis 3 is shown in Figure 6.

The $\mathrm{x}$ axis on the graphs represents all territorial units intersected by development axes and their closest surroundings. This axis is scale-less, so the resulting graph does not display the actual distance between territorial units. Nevertheless, the order of LAU2 is set according to their centroid distance from the border. The value of one of the socio-economic indicators is plotted on the y axis.

In Figure 6, the profiles for development axis 3 are depicted in order to demonstrate the variability in cross-border continuity types as described in the theoretical concept
(Fig. 1). As regards development axis 3, the ideal case for cross-border continuity of the socio-economic indicators is manifested by population density, the number of completed flats (at least in proximity to the border), and the proportion of built-up areas (with two peaks on both sides close to the border which are left out of consideration). A slightly progressive (or regressive, depending on the starting point) trend could be identified in the dependency ratio and, to some extent, in the rate of total population growth and the net migration rate. The valley type of cross-border continuity is mainly demonstrated by the proportion of agricultural land indicator in its generalised course without local peaks (although the "valley floor" is not directly on the border), the masculinity index in proximity to the border, and the crude marriage rate (again when considering the generalised course of the profile). There is one ridge type shape to the profile, which is the unemployment rate. Typical examples of the abrupt type is represented by two indicators - crude mortality rate and the coefficient of ecological stability. The remaining profiles could be classified as oscillating types. In the same fashion, all the other development axes with their respective socio-economic profiles can be analysed.

Looking at the individual indicators across all development axes, Table 2 summarises the most prevalent type of profile within a development axis (profiles read from left to right, i.e. from Poland to the Czech Republic). Table 2 could be read by row for an individual indicator across the development axes, or by column, providing a picture of

\begin{tabular}{|c|c|c|c|c|c|c|}
\hline \multirow{2}{*}{ 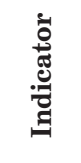 } & \multicolumn{6}{|c|}{ Development axis } \\
\hline & 1 & 2 & 3 & 4 & 5 & 6 \\
\hline $\mathrm{PD}$ & abrupt*/oscillating & constant ${ }^{* * *}$ & constant* & constant* & abrupt*/oscillating & abrupt* \\
\hline MI & regressive & ridge*/regressive & valley*/oscillating & constant** & valley* & valley*/oscillating \\
\hline CBR & $\begin{array}{l}\text { regressive*/ } \\
\text { constant }\end{array}$ & oscillating & $\begin{array}{l}\text { progressive*/ } \\
\text { oscillating }\end{array}$ & $\begin{array}{l}\text { abrupt*/ } \\
\text { progressive }\end{array}$ & constant** & progressive*/ridge \\
\hline CMR & progressive** & $\begin{array}{l}\text { regressive/ } \\
\text { constant }\end{array}$ & abrupt*/oscillating & abrupt*/oscillating & $\begin{array}{l}\text { constant*/ } \\
\text { oscillating }\end{array}$ & constant** \\
\hline RNI & regressive* & $\begin{array}{l}\text { constant*/ } \\
\text { progressive }\end{array}$ & abrupt*/oscillating & progressive & constant** & $\begin{array}{l}\text { progressive*/ } \\
\text { oscillating }\end{array}$ \\
\hline NMR & oscillating & ridge* & $\begin{array}{l}\text { abrupt*/ } \\
\text { progressive** }\end{array}$ & abrupt & abrupt*/oscillating & constant** \\
\hline RTG & oscillating & ridge* & progressive** $^{* *}$ & abrupt & abrupt*/oscillating & constant** \\
\hline CMR & regressive & abrupt*/oscillating & valley** & valley*/oscillating & abrupt*/oscillating & constant** \\
\hline IMR & abrupt*/oscillating & abrupt & oscillating & ridge*/constant & constant $* * *$ & abrupt*** \\
\hline $\mathrm{DR}$ & regressive*/valley & $\begin{array}{l}\text { abrupt*/ } \\
\text { progressive** }\end{array}$ & progressive $e^{* *}$ & progressive & $\begin{array}{l}\text { constant*/ } \\
\text { oscillating }\end{array}$ & progressive \\
\hline EAI & $\begin{array}{l}\text { abrupt*/ } \\
\text { progressive** }\end{array}$ & $\begin{array}{l}\text { Abrupt*/ } \\
\text { oscillating }\end{array}$ & $\begin{array}{l}\text { constant*/ } \\
\text { oscillating }\end{array}$ & $\begin{array}{l}\text { progressive*/ } \\
\text { oscillating }\end{array}$ & progressive*/ridge & $\begin{array}{l}\text { progressive*/ } \\
\text { oscillating }\end{array}$ \\
\hline UR & progressive $e^{* *}$ & valley*/regressive & ridge*/oscillating & abrupt*/regressive & $\begin{array}{l}\text { abrupt*/ } \\
\text { progressive }\end{array}$ & constant* \\
\hline NFC & oscillating & abrupt*/oscillating & constant* & abrupt & oscillating & abrupt** \\
\hline AGR & abrupt*/oscillating & oscillating & valley & valley & regressive*/valley & $\begin{array}{l}\text { constant*/ } \\
\text { regressive }\end{array}$ \\
\hline BUA & oscillating & $\begin{array}{l}\text { constant*/ } \\
\text { oscillating }\end{array}$ & constant* & constant*/valley & ridge $e^{* *}$ & ridge* \\
\hline CES & progressive & abrupt*/oscillating & abrupt* & ridge*/constant & constant*/ridge & constant** \\
\hline
\end{tabular}

Tab. 2: Types of socio-economic profiles within development axes (Notes: * Applicable only in proximity to the border, ** except the right end of the profile, *** except the left end of the profile)

Source: authors' calculations and visualisation 


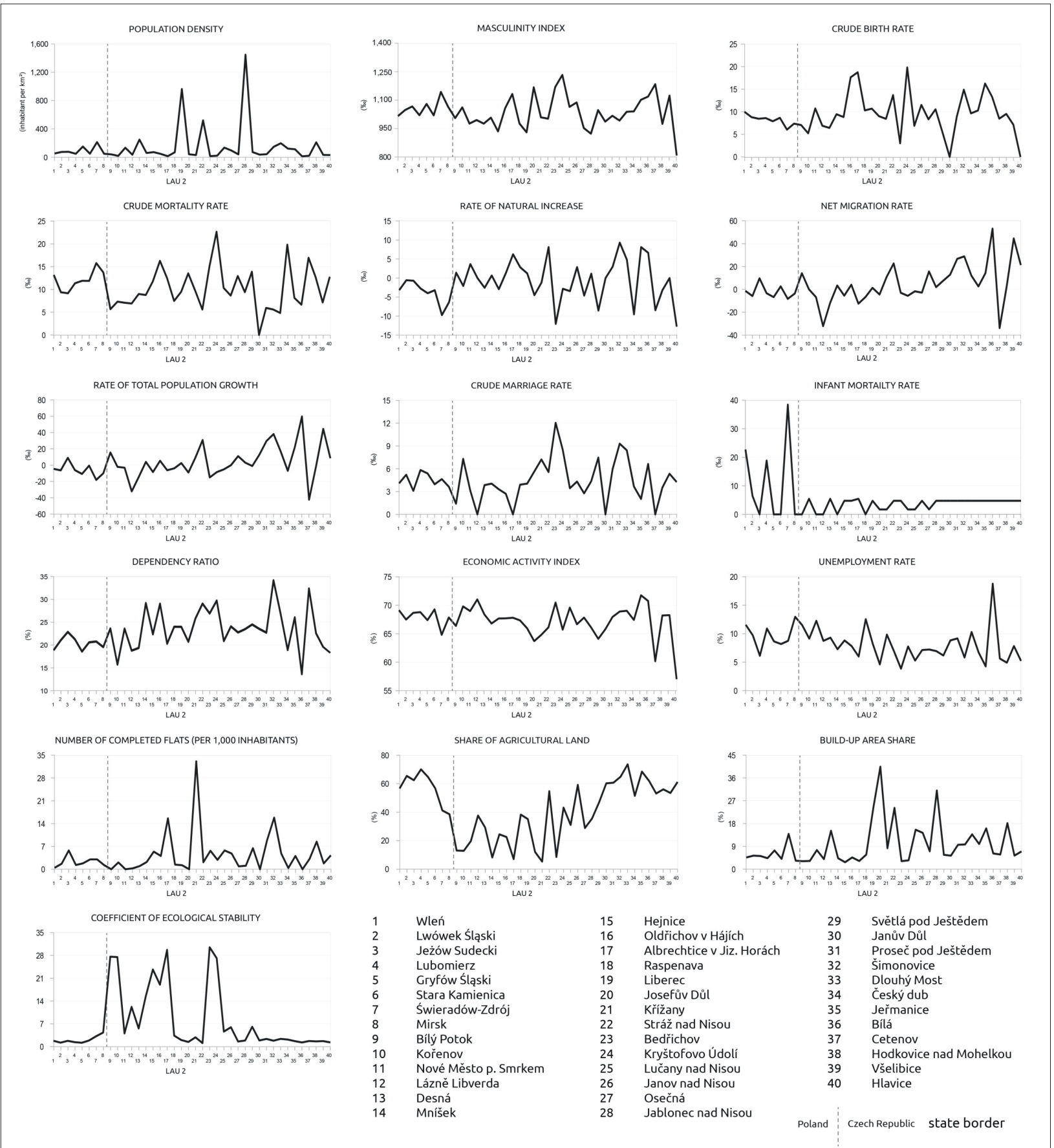

Fig. 6: Socio-economic profiles of sixteen selected indicators for development axis 3

Source: authors' calculations and visualisation

each development axis. At first glance the table is rather challenging to read, nevertheless certain patterns can be found. The most continuous indicators appear to be the proportion of built-up areas, the crude mortality rate, the coefficient of ecologic stability and the population density (all classified three times as constant types). In contrast, the greatest discontinuity is shown by the net migration rate, the infant mortality rate (albeit its values are very low in general), the number of completed flats and, paradoxically, the population density. All four indicators fall into the abrupt change type of socio-economic profiles. A comprehensive frequency analysis of all indicators and types derived from Table 2 is depicted in Figure 7.

It is important to note that interpretation using profiling is expert-based and is rather subjective. This requires some degree of generalisation to estimate overall trends in the examined socio-economic indicators. The evaluation of profiles also depends on the scale (range) of the trend analysis - how far from the border in a profile graph is the evaluation applied. It is recommended that the intensity of an indicator's value change in the context of the values ranges is also taken into consideration.

Moreover, all the socio-economic profiling is highly dependent on the sequence order of the selected units, and on the direction/course of an axis to be studied (as mentioned earlier, the authors used centroids of LAU2 units and their distance from the border).

\subsubsection{Correlation and Cluster analysis}

Before the statistical analysis was performed, it was necessary to prepare an input dataset. First, unnecessary attributes/indicators were removed for the correlation and 


\begin{tabular}{|c|c|c|c|c|c|c|c|c|c|c|c|c|c|c|c|c|}
\hline & PD & MI & CBR & CMR & RNI & NMR & RTG & CMR & IMR & DR & EAI & UR & NFC & AGR & BUA & CES \\
\hline constant & 3 & 1 & 2 & 3 & 2 & 1 & 1 & 1 & 1 & 1 & 1 & 1 & 1 & 1 & 3 & 3 \\
\hline $\begin{array}{l}\text { progressive } \\
\text { /regressive }\end{array}$ & 0 & 2 & 4 & 2 & 4 & 1 & 1 & 1 & 0 & 5 & 4 & 4 & 0 & 2 & 0 & 1 \\
\hline ridge & 0 & 1 & 1 & 0 & 0 & 1 & 1 & 0 & 1 & 0 & 1 & 1 & 0 & 0 & 2 & 2 \\
\hline valley & 0 & 3 & 0 & 0 & 0 & 0 & 0 & 2 & 0 & 1 & 0 & 1 & 0 & 3 & 1 & 0 \\
\hline oscillating & 2 & 2 & 2 & 3 & 2 & 2 & 2 & 3 & 2 & 1 & 4 & 1 & 3 & 2 & 2 & 1 \\
\hline abrupt & 3 & 0 & 1 & 2 & 1 & 3 & 2 & 2 & 3 & 1 & 2 & 2 & 3 & 1 & 0 & 2 \\
\hline
\end{tabular}

Fig. 7: Frequency analysis of types of socio-economic profiles (development axis 3)

Source: authors' calculations and visualisation

clustering analysis. Second, a recalculation of absolute values into relative values was carried out, such as the number of births and deaths into crude birth and mortality rates.

In the next step, the interdependence of the remaining indicators was examined. The Pearson correlation coefficient was calculated to describe the degree of linear dependence between each pair of indicators (Cohen et al., 2003). If two indicators are highly dependent on each other, they do not add any additional information to the data file, so the presence of both is not necessary. By displaying the correlation matrix, indicators with a strong interrelationship were easily identified. As part of the data preparation phase, three sets of data were prepared using the correlation analysis results to enter the consequent cluster analysis. The first included all the indicators obtained, regardless of the degree of correlation or the logic of their suitability for use (43 indicators). In the second group, indicators with a strong correlation coefficient were excluded and the threshold value of this coefficient was determined as 0.7 (14 indicators remained). The last group was determined expertly - it also contained indicators with a strong correlation coefficient value (the highest correlation between net migration rate and rate of total growth was 0.96 ). The authors wanted to take expert knowledge into account as well, however, and kept this information because of its significance in the cluster analysis used in this paper (16 indicators, see Fig. 8). All analyses in this paper (cartographic visualisation, socioeconomic profiles, and cluster analysis) were performed based on these sixteen expertly selected indicators as the most comprehensive combination of human and computerbased decision making.

In assessing the cross-border continuity statistically, a similarity between LAU2 areas in relation to all monitored attributes was examined using multidimensional data aggregation - cluster analysis. Clustering simplifies the attribute information and allows behaviour to be monitored across borders. For grouping of values based on one variable, several methods have been introduced, e.g. by Cox (1957) and Fisher (1958). Cluster analysis provides the user with empirical and objective methods to perform one of the basic data processing procedures - classification. Militky and Meloun (2011) state that cluster analysis is one of the

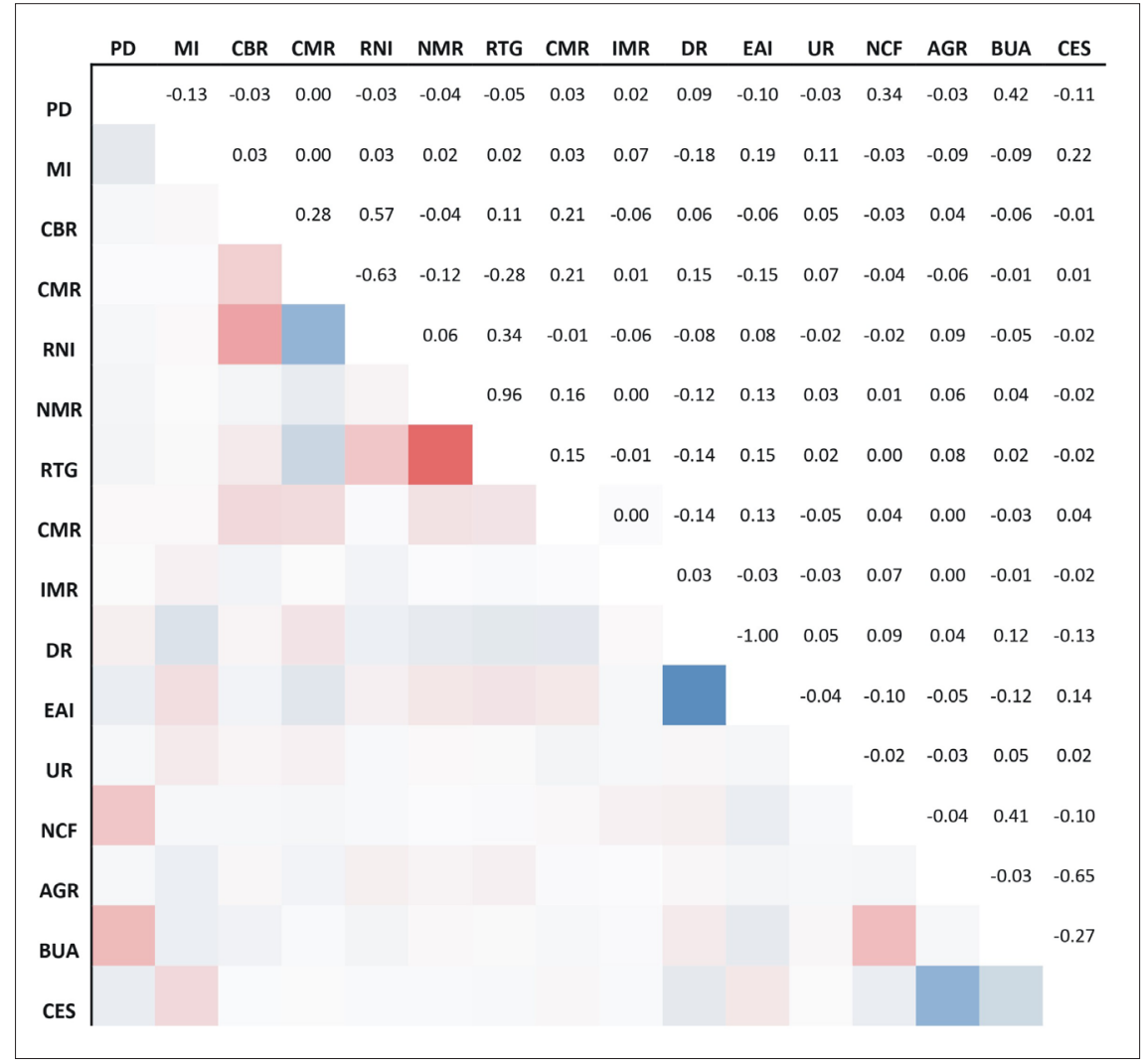

Fig. 8: Correlation coefficients between 16 selected attributes (Notes: Red colours for positive and blue colours for negative correlations; richer colours indicate stronger correlations)

Source: authors' calculations and visualisation 
methods involved in investigating the similarities among multidimensional objects (objects with a large number of variables) and classifying their features into clusters.

For cross-border continuity analysis, the authors chose hierarchical clustering due to the unknown target number of clusters to be created (in contrast to the partition methods which require certain user parameters, such as target number of clusters) (Aggrawal and Reddy, 2014). Hierarchical classification creates clusters that are hierarchically organised, i.e. clusters at the higher level always contain clusters from the lower levels. The objects are classified in a "bottom-up" order - the first clusters are created from individual entities, and in the next iterations, based on their similarities, these clusters are aggregated together.

Ward's method was selected for the clustering because it minimises the heterogeneity of clusters by using analysis of variance (Ward, 1963). At each step, a possible pair of objects (clusters) is considered to minimise the sum of the squares of deviation from the mean value within the cluster (Militky and Meloun, 2011). The distance matrix was calculated by the Euclidean metric. The clustering process is graphically represented by a dendrogram, which helps in determining the target/optimal number of clusters (see Fig. 9).

Since the dendrogram for a large number of records (LAU2 units) is rather difficult to interpret, a decision about the optimal number of clusters was made in order to generalise the information from the dendrogram. The optimal number of clusters was based on the silhouette measure (Rousseeuw, 1987) of cohesion and separation, which supports the decision-making process concerning the target number of clusters. The silhouette index statistically evaluates the quality of each cluster, expressed by the silhouette value, ranging from -1 (poorly clustered observations) to 1 (wellclustered observations). The silhouettes are constructed when compact and clearly separate clusters are desired, and the advantage of this method is that it only depends on the actual partition of the objects (not on the clustering algorithm that was used to obtain it). Consequently, the silhouette index could be used to improve the results of cluster analysis, or to compare the output of different clustering algorithms applied to the same data (Rousseeuw, 1987).

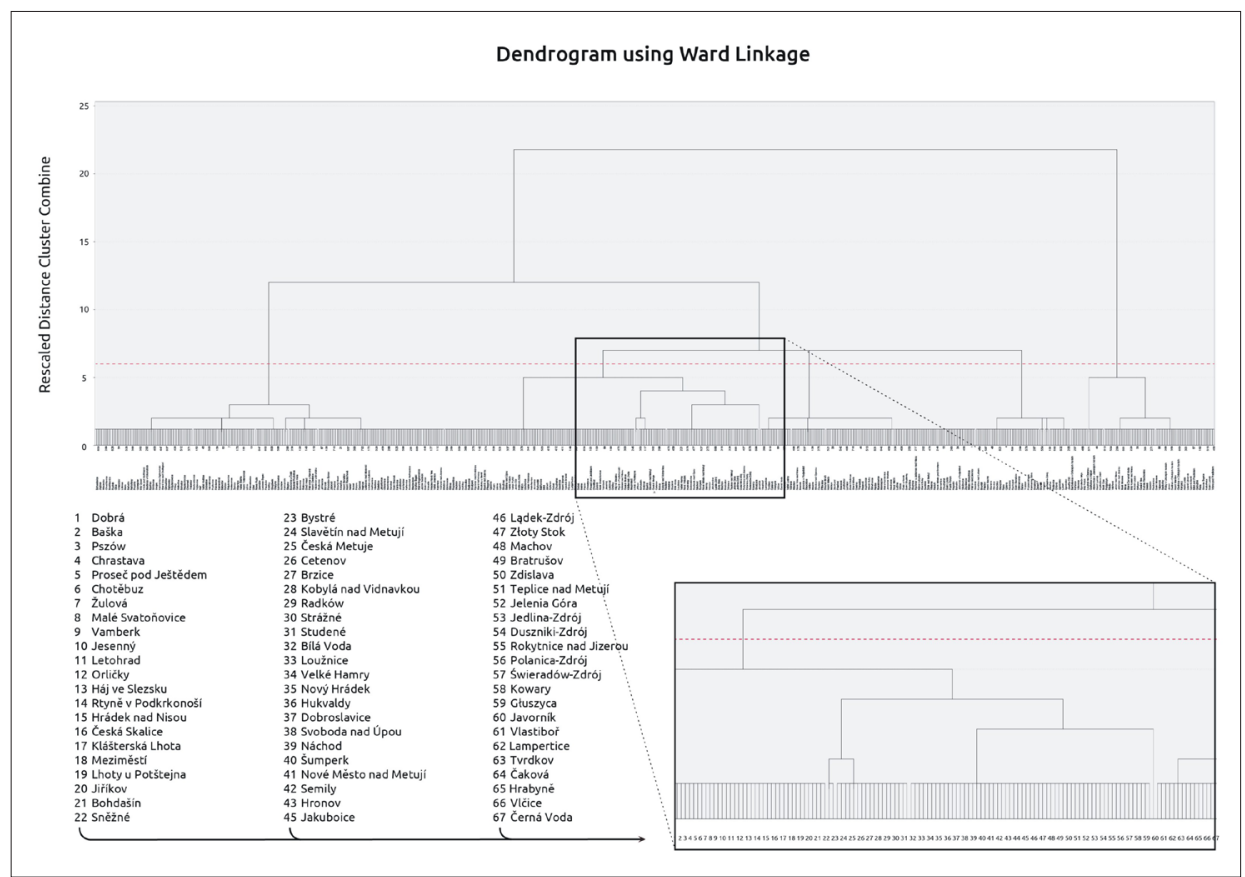

Fig. 9: Dendogram from clustering analysis using Ward's method with example of detailed cluster structure Source: authors' calculations and visualisation

For each set of data (all indicators, non-correlated indicators, and the authors' selections), clustering for 3-10 clusters was tested (more clusters than 10 tend to be difficult to interpret). The results showed that the highest quality of clustering took place on data with 16 indicators, expertly selected, so these were chosen for the visualisation and evaluation of the cross-border continuity. Using the evaluation methods (the silhouette index value is in Fig. 10), the value of 5 was decided upon as the optimal number of clusters. This amount is also readable in the subsequent cartographic visualisation (Fig. 11).

The dendrogram is not intuitively readable, so it is not useful for the evaluation of cross-border spatial continuity and the cluster membership of LAU2 was displayed on the map. Nevertheless, perception difficulties also emerged from direct map visualisation of the clustering results. When every single LAU2 colour was placed according to their cluster

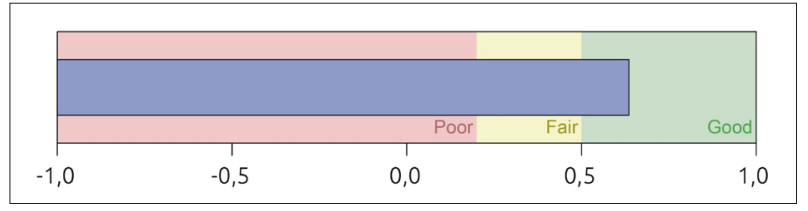

Fig. 10: Evaluation of quality of clustering into five groups using the silhouette measure of cohesion and separation. Source: authors' calculations and visualisation

membership, the resulting map appeared too complex due to the heterogeneity of unit sizes. Thus, individual small LAU2 units disrupted the overall perception of spatial continuity so it did not meet the requirements for its proper evaluation. Therefore, a semi-automated process (toolbox) in the Esri ArcMap Model Builder environment was designed to improve the final visualisation of the clustering analysis. 


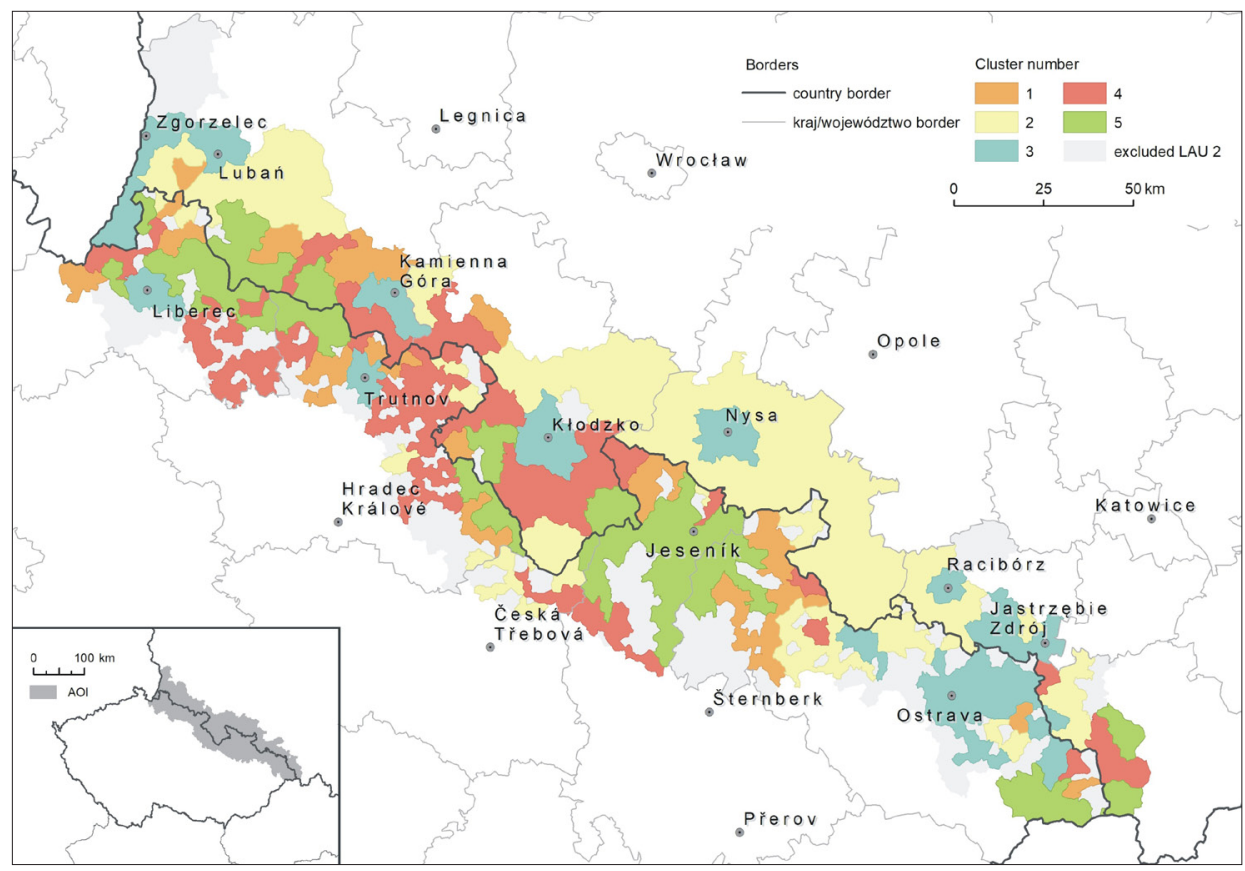

Fig. 11: Resulting clusters using Ward's method after improvement using authors' toolbox Source: authors' calculations and visualisation

First, the toolbox dissolved administrative boundaries of input data according to cluster membership. Basic statistical information (minimum, maximum and mean) was also added for each indicator entering the cluster analysis. This was in order to keep both the indicators' contribution to further interpretation, and the cluster membership, in the single attribute table. Second, the toolbox selected only LAU2 with a minimal area of 30 square kilometres and which were within six kilometres of the border. These thresholds were set expertly by the authors after a series of tests. Nevertheless, both parameters can be modified in a dialogue box by the user, based on the specifics of a given study area. The final map of LAU2 with cluster membership is shown in Figure 11 and a basic summary of the clustering results is in Table 3.

The dendrogram is not intuitively readable, so it is not useful for the evaluation of cross-border spatial continuity and cluster membership of LAU2 was displayed on the map. Nevertheless, perception difficulties also emerged from direct map visualisation of the clustering results. When every single LAU2 colour was placed according to their cluster membership, the resulting map appeared too complex due to the heterogeneity of unit sizes. Thus, individual small LAU2 disrupted the overall perception of the spatial continuity so it did not meet the requirements for its proper evaluation. Therefore, a semi-automated process (toolbox) in the Esri ArcMap Model Builder environment was designed to improve the final visualisation of the clustering analysis.
First, the toolbox dissolved administrative boundaries of input data according to cluster membership. Basic statistical information (minimum, maximum and mean) was also added for each indicator entering the cluster analysis. This was in order to keep both the indicators' contribution to further interpretation, and the cluster membership, in the single attribute table. Second, the toolbox selected only LAU2 with a minimal area of 30 square kilometres and which were within six kilometres of the border. These thresholds were set expertly by the authors after a series of tests. Nevertheless, both parameters can be modified in a dialogue box by the user, based on the specifics of a given study area. The final map of LAU2 with cluster membership is in Figure 11 and a basic summary of the clustering results is in Table 3 .

From the perspective of the individual indicators, cluster 1 is characterised by the lowest values in population density, number of completed flats and proportion of built-up area in the analysed area. Cluster 2 contains LAU2 units with high values in phenomena that emphasise the importance of agricultural production. From the demographic point of view, there is a population decrease in the area and higher values of the dependency index. In cluster 3 , there are significantly high values in population density, ratio of built-up area and number of completed flats. As a result of the suburbanization process, population decline occurs in larger settlements. Cluster 4 is mainly composed of sub-mountainous areas with the prevalence of natural landscapes. It is similar to cluster 1 , but with a higher

\begin{tabular}{ccrl}
\hline Cluster & Area (\%) & LAU2 count & \multicolumn{1}{c}{ Characteristics } \\
\hline 1 & 13.9 & 138 & Sub-mountainous, rather smaller units, with significant share of natural sites \\
2 & 33.9 & 224 & Agricultural units, mainly on Polish side of border \\
3 & 13.5 & 58 & Urban units \\
4 & 19.8 & 201 & Hilly, natural landscape prevalence, larger units \\
5 & 18.9 & 92 & Highest parts of mountains, conservation areas (protected-by-law parks) \\
\hline
\end{tabular}

Tab. 3: Summary characteristics of the clustering results

Source: authors' calculations 
population density due to the influence of cities within this category. For this reason, there is a larger proportion of built-up area compared to the first cluster. Cluster 5 is characterised by mountains and other natural landscapes and there is little noticeable human interference. It has the lowest proportions of both built-up and agricultural lands in this whole area of interest. Low settlement levels cause it to have the lowest population density in comparison with all other clusters.

The cluster analysis provided comprehensive results which generalised the information from all sixteen indicators into compact outputs - the dendrogram and the final map. Both clustering and visualisations offered an overall picture of cross-border (dis)continuity in socioeconomic indicators, and it proved feasible to employ them in combination with individual evaluation using choropleth maps and the profiling method.

\section{Results and discussion}

Three different methods, their characteristics and the main outputs were described in the sections above, mainly from a methodological perspective but also with a description of the interpretation of individual outputs. In addition to the previous section, a combination of socio-economic profiling and clustering analysis is further presented as a synthetic outcome, encapsulating important findings from individual methods. This section summarises the main geographical results from all three analyses. Euroregions are taken as the main geographical reference units since they cover almost all the study area. Moreover, Euroregions are internationally known, so this should help readers to easily locate the results in a geographical context (instead of referring to municipalities or national sub-regions using local nomenclature and geographic names).

Sixteen selected phenomena represented by socioeconomic indicators were visualised via choropleth maps. The cartographic visualisation revealed sub-regions with almost perfect continuity of socio-economic indicators (i.e. values of an indicator are at the same interval). Specifically, the easternmost part of the study area around the city of Ostrava (partly falling into Euroregion Teschinensis and partly into Euroregion Silesia; around development axis 1) is the most typical sub-region with cross-border spatial continuity in most of the indicators (e.g. population density, marriage rate, dependency ratio). This is due to the fact that the sub-region is highly urbanised and shares similar environmental, social and economic conditions. For this part of the borderlands, it is also important to point out the historical background, because this part of the region represents the long-standing Czech-Polish 'touch' region and, unlike other parts of the Czech-Polish borderlands (mainly the western parts), which were mostly part of Sudetenland, it was not inhabited by Germans. On the other hand, an example of a sub-region showing rather more discontinuity of socio-economic indicators (especially in the case of Kłodzko county in the central part of the study area), is part of the Euroregion Glacensis (western-central part of the study area, development axis 4). In comparison with the previously mentioned Euroregions, Glacensis is a mountainous region with well-preserved nature, but with significant societal differences. Cross-border spatial continuity for the remaining parts of the study area is only apparent in the limited number of socio-economic indicators and larger scales (greater detail), so it is better to refer to discontinuity in these cases.
As a result of the socio-economic profiling, line graphs were constructed (an example of development axis 3 was given in Fig. 6). In each of them intensity and trend curve are used to better understand the (dis)continuity of the phenomena in a given transect. An example of the presence of both continuity and discontinuity is development axis 3 , almost entirely belonging to Euroregion Neisse-Nisa-Nysa in the western part of the study area. The average values of socio-economic indicators (population density, number of completed flats, and proportion of built-up area) show a constant trend and differ only minimally in their close proximity to the border. On the other hand, in the same region but after "crossing" the border, other indicators do change in their intensity (e.g. crude mortality rate, net migration rate, coefficient of ecological stability). Unlike the choropleth maps, socio-economic profiling did not provide examples of sub-regions that can be clearly classified as continuous or vice versa. Socio-economic profiles (Tab. 2) indicate that development axis 6 (contained by Euroregion Silesia) is the most continuous and this corresponds with the results from the visual analysis of choropleth maps. Greater cross-border continuity, as expressed by several constant trends of socio-economic profiles, is shown by development axis 5 (Euroregion Praded). Yet at the same time almost the same number of abrupt types of profile are detected for this axis, and a considerable number of oscillating types are also present. In contrast, development axis 1 (Euroregion Teschinensis) appears to be very discontinuous which is, paradoxically, in contradiction with observations based on choropleth maps. Significant discontinuity can be found in development axis 2 (partly in Euroregion Glacensis) and this is in accordance with previous findings. The remaining axes cannot be distinguished in this fashion since they are quite diverse in terms of profile type.

Cluster analysis permitted a more comprehensive evaluation of the continuity as it is not intuitive (if possible) to evaluate it by looking at individual indicators separately. This analysis created five groups of LAU2 (excluding those with an area less than 30 square kilometres) according to the values of socio-economic indicators - all combined together. Looking at the detailed cluster composition, it was possible to evaluate the significance of some attributes in cluster formation. Some indicators hardly contributed to the dissimilarity of the clusters (e.g. crude birth rate, crude mortality rate, net migration rate or marriage rate), while others were quite important and influenced the classification (e.g. dependency ratio and proportion of agricultural land). The remaining indicators helped to describe individual clusters. Regarding the cluster types, the most crossborder continuous sub-region is located in the east of the study area (Euroregions Teschinensis and Silesia, around development axis 1 ) with a prevalence of cluster numbers 2 and 3. Cluster number 3 is mainly composed of urban LAU2, thus the values of the socio-economic indicators are similar. In contrast, cluster number 2 mainly contains agricultural units, but in the case of Euroregion Silesia, the cross-border continuity is evident (with some exceptions). Cross-border continuity can also be seen in the western half of the study area. In the western parts of Euroregion Glacensis (development axis 2), LAU2 are mostly members of cluster number 4 , which is typically composed of sub-mountainous LAU2 and the presence of several towns increases the importance of urban-related indicators (e.g. population density, built-up area proportion, number of completed flats). Further west, cluster number 5 is dominant in the Euroregion Neisse-Nisa-Nysa (development axis 3), mainly 
enclosing the border. This part is typically composed of mountainous LAU2 representing rural villages with wellpreserved natural landscapes.

The most spatially discontinuous borderlands are located entirely in Euroregion Praded (central-eastern part of the study area, development axis 5). There is distinct crossborder discontinuity and the border literally separates the region into Czech and Polish parts, where the former is predominantly mountainous in character and the latter is more or less agricultural (except for the town of Nysa). Of course, physical geography does not necessarily imply the formation of certain socio-economic conditions, but the opposite is true in this case. It is necessary to mention that the road infrastructure is insufficient and in combination with the dispersed settlements, it hinders the socio-economic development of the region. Finally, a mixture of cross-border continuity and discontinuity occurs both in the westernmost and easternmost parts of the study area. Additionally, the eastern part of Euroregion Glacensis (development axis 2) appears to be a compound of continuity and discontinuity.

A fusion of development axes and clustering analysis enabled the analysis of cross-border transition in a wider socio-economic and spatial context, in comparison with non-spatial socio-economic profiling. For this purpose, each development axis was supplemented with pie charts, illustrating the composition of cluster types of member LAU2 units (see Fig. 12). Generally, this combination (development axes with clustering analysis) confirms the results of previous analyses. The most continuous development axes tend to be numbers 1 and 6 , and, as already mentioned, these are parts of Euroregions Teschinensis and Silesia. The prevalence of LAU2 from cluster number 3 (urban units) can be seen in the case of development axis 1 , whereas development axis 6 mainly contains LAU2 from cluster number 2 (agriculture/rural units). Structural similarity, in the sense of the composition of LAU2 cluster membership, can be found in the case of development axes 3 and 5. Nevertheless, development axis 5 is, according to the socio-economic profiling, halfway between cross-border continuity and discontinuity, and with respect to the cluster analysis it represents a typical example of cross-border spatial discontinuity. On one hand, development axis 3 contains the greatest variety of socioeconomic profiles, but on the other hand it belongs to one of the more continuous cross-border sub-regions in the study area, according to the cluster analysis (with a prevalence of cluster number 5 around the border). Cluster type 4 is predominant in the LAU2 composition of development axis 2 , therefore it corresponds with previous results quite well. The character of Euroregion Glacensis, which is partly cross-border continuous and partly discontinuous, determined the results for development axis 4. Spatially, cluster types 4 and 2 oscillate as we move further from the border, also causing the axis to be difficult to classify.

To summarize the most important findings from all analytical procedures, the following specific points can be mentioned:

- The greatest cross-border spatial continuity of socioeconomic indicators is present in the eastern part of the study area (Euroregions Silesia and Teschinensis, around development axis 1). This is in accordance with Tykkyläinen (2009, p. 349), who stated that “...in more industrialised areas there is usually a certain daily crossing of labour over the border", which is exactly the case in this part of the Czech-Polish borderland. In particular, the Euroregion Teschensis, a former unified region sharing a common history, shows "better conditions for mutual interpersonal and business contact than elsewhere..." (Siwek, 2018, p. 169). Moreover, the communication infrastructure (highspeed roads and railways) is much more developed in this region compared to other parts (Jeřábek, Havlíček and Dokoupil, 2018). Having little or no language barrier (Böhm, 2015) also contributes to outstanding relationships on both sides of the border;

- The most discontinuous cross-border region is in the central-eastern part of the study area (Euroregion Praded), where the border acts as a socio-economic barrier of (spatial) continuity. These findings are in

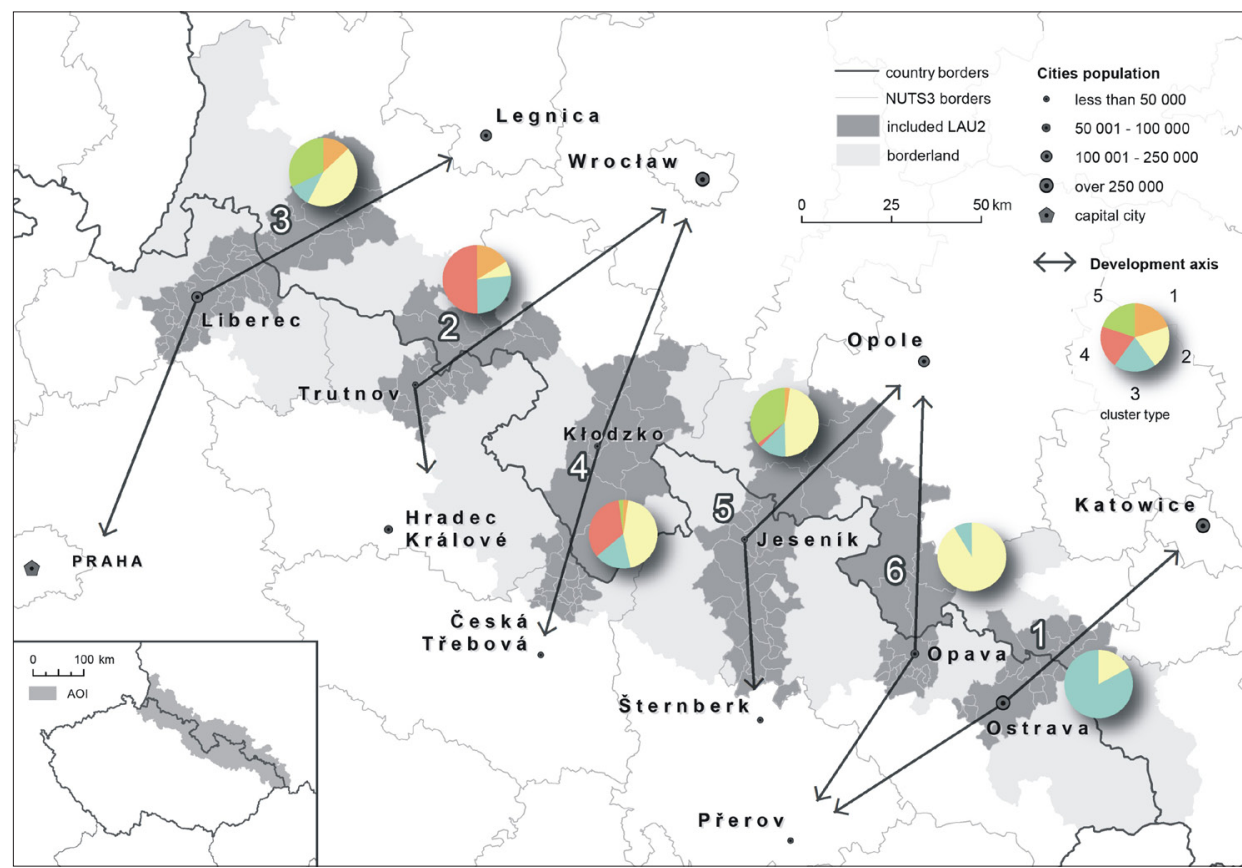

Fig. 12: Proportion of cluster types of LAU2 at the development axes

Source: authors' calculations and visualisation 
line with Mintálová and Ptáček (2012), and Kladivo et al. (2012), who also mentioned the structural problems of this region, although it has a high potential for tourism which could even out the differences between the Czech and Polish parts. The non-continuous higher-level road infrastructure also causes discrepancies, especially when considering roads of secondary importance on the Polish side (Jeřábek, Havlíček and Dokoupil, 2018);

- Euroregions Neisse-Nisa-Nysa and Glacensis are examples of mixed cross-border (dis)continuity, depending on the selected indicator, method and distance from the border. As Böhm (2015) states, there is still a significant language barrier in the Euroregion Neisse-Nisa-Nysa and it is a co-operation obstacle, which may contribute to the lack of fully developed cross-border cooperation (albeit this region was amongst the first Euroregions in postSoviet countries). Thus, these regions are represented by mixed (dis)continuity in socio-economic indicators; and

- Generally, the analyses presented have demonstrated that "... most of the borderlands of the Czech Republic... are considered to have high development potential due to their favourable geographical position combined with low economic performance." (Tykkyläinen, 2009, pp. 350-351), which is still a valid argument today.

From the methodological point of view, the main points to be stressed are:

- Socio-economic profiling provides a detailed view of (dis) continuity based on the values of non-restricted, concrete indicators. A certain level of expert knowledge is needed for interpretation, however, which may imply rather subjective conclusions. Thus, socio-economic profiling should be compared with other (objective) methods;

- Choropleth maps allow one to display smoother transitions of socio-economic indicators across the border, since they use classified scale ranges with broader intervals in contrast to socio-economic profiling;

- Cluster analysis seems to be the most comprehensive method for cross-border spatial continuity detection, as it takes all indicators for all LAU2 into consideration;

- Proximity to the border and the scale of interpretation are crucial for (dis)continuity evaluation. In most cases, some visual/cognitive generalisation is needed; and

- The combination of all outputs and results from the three main analytical steps represents a complex procedure but provides valuable views for the thorough evaluation of cross-border (spatial) continuity using socio-economic indicators.

\section{Conclusions}

An analysis of cross-border (spatial) continuity of socio-economic indicators was performed in order to determine whether the border sub-regions shared common characteristics expressed by the statistical data. The main aim of cross-border cooperation is to balance the overall quality of life in participating sub-regions. One possible way to evaluate cross-border cooperation is to use "hard" statistical data. The authors of this study used quantitative methods in combination with GIS analysis, cartographic visualisation and socio-economic profiling in order to assess cross-border cooperation. The mutual deployment of these methods appears to be helpful for this purpose and could be applied to any type of borderlands across Europe or even worldwide. Beside the main geographical conclusions, this paper demonstrated a universal procedure of Spatial Data Science, as an umbrella term for quantitative, GIS-based, data-driven and visual analysis.

To summarise the main research objective - whether there is cross-border continuity in socio-economic phenomena (represented by respective indicators) in the Czech-Polish border regions - a thorough analysis and interpretation was performed. According to the results, the answer is both "yes and no", depending on the sub-region, proximity to the border, method used and selected indicator. While mentioning selected indicators, the most important indicator for crossborder continuity evaluation appears to be population density (in all types of presented methods), and this is in line with its wide and general application in geo-demographic studies. To answer other specific research sub-questions, the combination of presented methods adequately captures current state-ofthe-art of cross-border continuity, at least from a quantitative point of view. Interpretation itself can be assessed with the notion that the expert is familiar with methods used and is aware of potential limitations of such tools. It is indeed important to invite relevant experts on cross-border topics and also policies that are rather trans-national (or regional in sense of the "shared" borderlands)

In general, the typical areas of cross-border (spatial) continuity, where most of the phenomena are fluently crossing the border, are located in the eastern part of the CzechPolish borderlands (Euroregions Silesia and Teschinensis, around development axis 1). Geographically next to them, in the central part of the study area, the most discontinuous region is located (Euroregion Praded, development axis 5). Further west, namely Euroregions Glacensis (development axis 4) and Neisse-Nisa-Nysa (development axis 3), their cross-border (spatial) continuity depends on their proximity to the border, method used, and selected indicator analysed individually, and thus they can be treated as mixed types of (spatial) continuity. A future step to understand clearly crossborder continuity can be to realise a qualitative research project in the model areas. Especially at a regional scale, in selected most interesting model areas, further investigation could shed new light on specific cross-border co-operation (as qualitative research could cover all of the borderlands).

\section{Acknowledgements}

The authors gratefully acknowledge the support by the ERASMUS+ project "Spationomy", No. 2016-1-CZ01KA203-024040, funded by the European Union and also by the project "Geodemo" funded by the Czech Science Foundation (GACR), grant No. 18-12166S. The authors also thank Katerina Soukupová for initial data preparation.

\section{References:}

AEBR AND EUROPEAN COMMISSION (2000): Practical guide to cross-border cooperation. Association of European Border Regions.

AGGARWAL, C. C., REDDY, C. K. [eds.] (2013): Data clustering: algorithms and applications. CRC press.

ANDERSON, J., WEVER, E. (2003): Borders, border regions and economic integration: one world, ready or not. Journal of Borderlands Studies, 18(1): 27-38.

BELL, J. L. (2010): Continuity and infinitesimals, continuity and infinitesimals [online]. The Stanford encyclopedia of philosophy [cit. 16.10.2018]. Available at: http://plato. stanford.edu/archives/fall2010/entries/continuity/ 
BÖHM, H. (2015): Czech-Polish borders: Comparison of the EU funds for cross-border co-operation of schools in selected Euroregions (pp. 51-71). In: Cross-Border Review Yearbook 2015.

BRUNCLÍK, F., MACHÁT, F. (1930): Zeměpisný atlas pro školy střední, ústavy učitelské a školy obchodní, Praha.

CARRERA, S., BLOCKMANS, S., GROS, D., GUILD, E. (2015): The EU's Response to the Refugee Crisis: Taking Stock and Setting Policy Priorities [online]. CEPS Essay [cit. 10.8.2018], 20(16). Available at: https://ssrn.com/ abstract $=2715460 /$

COE (1972): 1. Europäisches Symposium der Grenzregionen. Die Zusammenarbeit europäischer Grenzgebiete. Strasbourg: Council of Europe.

COHEN, J., COHEN, P., WEST, S. G., AIKEN, J. (2003): Applied multiple regression/correlation analysis for the behavioral sciences, $3^{\text {rd }}$ Edition, Lawrence Erlbaum Associates.

CORDELL, K., WOLFF, S. (2005): Ethnic Germans in Poland and the Czech Republic: a comparative evaluation. Nationalities Papers, 33(2): 255-276.

COX, D. R. (1957): Note on grouping. Journal of the American Statistical Association, 52(280): 543-547.

ČSÚ (2005): Obyvatelstvo a bydlení v okresech českopolského pohraničí, ČSÚ - Krajská reprezentace Liberec.

DIBIASE, D. (2014): The Nature of Geographic Information: An Open Geospatial Textbook [online]. The Pennsylvania State University, State College [cit. 10.7.2018]. Available at: https://www.e-education.psu.edu/natureofgeoinfo

DIENER, A. C., HAGEN, J. (2012): Borders: A very short introduction. Oxford University Press.

DOKOUPIL, J. HAVLÍČEK, T. (2002): Border and border region: theoretical aspects, identification and determination. Acta Universitatis Carolinae, Geographica, 37(1): 27-44.

DOŁZBŁASZ, S. (2013): Cross-border co-operation in the Euroregions at the Polish-Czech and Polish-Slovak borders. European Countryside, 5(2): 102-114.

DVORSKÝ, J., PÁSZTO, V., SKANDEROVÁ, L. (2014): Geodata Scale Restriction Using Genetic Algorithm. In: Innovations in Bio-inspired Computing and Applications (pp. 215-223). Cham, Springer.

EUROSTAT (2015): Statistics Explained: Glossary: Local administrative unit (LAU) [online]. [cit. 12.9.2018]. Available at: http://ec.europa.eu/eurostat/statisticsexplained/index.php/Glossary:Local_administrative_ unit_(LAU)

FISHER, W. D. (1958): On grouping for maximum homogeneity. Journal of the American statistical Association, 3(284): 789-798.

GLASSHEIM, E. (2016): Cleansing the Czechoslovak Borderlands: Migration, Environment, and Health in the Former Sudetenland. University of Pittsburgh Press.

GOODCHILD, M. F. (1992): Geographical information science. International journal of geographical information systems, 6(1): 31-45.

GUICHONNET, P., RAFFESTIN, C. (1974): Géographie des frontières.

HAINING, R. P. (2003): Spatial data analysis: theory and practice. 1st Edition, Cambridge University Press.
HAVLÍČEK, T., JEŘÁBEK, M., DOKOUPIL, J. [eds.] (2018): Borders in Central Europe After the Schengen Agreement. Springer International Publishing.

HEFFNER, K. (1998): Kluczowe problemy demograficzno osadnicze obszarów przygranicznych Polska-Czechy. Opole, PIN / Instytut Śląski.

INSTITUTE FOR SPATIAL DEVELOPMENT, et al. (2014): Common Spatial Development Strategy of the V4+2 Countries, Brno.

JASCHITZ, M. (2013): Key factors for successful territorial cohesion: cross-border cooperation-how can some EU instruments create a new geography. European Journal of Geography, 4(4): 8-19.

JENKS, G. F. (1967): The data model concept in statistical mapping. International yearbook of cartography, 7(1): 186-190.

JEŘÁBEK, M., HAVLÍČEK, T., DOKOUPIL, J. (2018): Euroregions as a Platform for Cross-Border Cooperation. In: Borders in Central Europe After the Schengen Agreement (pp. 67-91). Cham, Springer.

KLADIVO, P., PTÁČEK, P., ROUBÍNEK, P., ZIENER, K. (2012): The Czech-Polish and Austrian-Slovenian borderlands - similarities and differences in the development and typology of regions. Moravian Geographical Reports, 20(3): 22-37.

KAUFMAN, L., ROUSSEEUW, P. J. (2009): Finding groups in data: an introduction to cluster analysis (Vol. 344). John Wiley \& Sons.

LONGLEY, P. A., GOODCHILD, M. F., MAGUIRE, D. J. RHIND, D. W. (2015): Geographic Information Science and Systems. John Wiley \& Sons.

MAREK, L., PÁSZTO, V., TUČEK, P. (2015): Using clustering in geosciences: Examples and case studies. $15^{\text {th }}$ International Multidisciplinary Scientific Geoconference and EXPO, SGEM 2015. 2(2): 1207-1214.

MARTINEZ, O. J. (1994): The dynamics of border interaction. New approaches to border analysis. In: Schofield, C. H. [ed.]: Global boundaries. World boundaries (pp. 1-15). London, Routledge.

MELOUN, M., MILITKY, J. (2011): Statistical data analysis: A practical guide. Woodhead Publishing.

MINGHI, J. V. (1963): Boundary studies in political geography. Annals of the Association of American Geographers, 53(3): 407-428.

MINISTRY OF REGIONAL DEVELOPMENT OF THE CZECH REPUBLIC, INSTITUTE FOR SPATIAL DEVELOPMENT (2015): Spatial Development Policy of the Czech Republic, Updated Version 1, Prague, Brno.

MINTÁLOVÁ, T. PTÁČEK, P. (2012): Perception of crossborder cooperation in the Czech and Polish border area on the example of the Jeseníky region. Acta Universitatis Palackianae Olomucensis - Geographica, 43(1): 31-49.

PÁSZTO, V., BRYCHTOVÁ, A., TUČEK, P., MAREK, L., BURIAN, J. (2015): Using a fuzzy inference system to delimit rural and urban municipalities in the Czech Republic in 2010. Journal of Maps, 11(2): 231-239.

PERKMANN, M. (2002): Euroregions: institutional entrepreneurship in the European Union. In: 
Perkmann, M. Sum, N. [eds.]: Globalization, regionalization, and cross-border regions (pp. 103-127). Basingstoke, Palgrave MacMillan.

PERKMANN, M. (2003): Cross-border regions in Europe significance and drivers of regional cross-border cooperation. European Urban and Regional studies, 10(2): 153-171.

PRESCOTT, J. R. V. (1965): The geography of frontiers and boundaries. London, Hutchinson.

PTÁČEK, P., KLADIVO, P., ROUBÍNEK, P., SIWEK, T., ZIENER, K. (2017): Granica w świadomości iw rzeczywistości: dwa przykłady z nowych krajów członkowskich Unii Europejskiej. Studia Socjologiczne, 1(224): 167-193.

ROBINSON, A. H. M., MUEHRCKE, J. L., KIMERLING, P. C., GUPTILL, A. J. (1995): Elements of cartography, $6^{\text {th }}$ Edition, Wiley.

ROUSSEEUW, P. J. (1987): Silhouettes: a graphical aid to the interpretation and validation of cluster analysis. Journal of computational and applied mathematics, 20: 53-65.

RUNGE, J. (2003): Slask Cieszynski jako czesko-polski region przygraniczny. In: Runge, J. [ed.]: Terytorialny systém spoleczno-ekonomiczny pogranicza wojewódstwa Śląskiego i Północnych Moraw oraz strategie jego rozwoju (pp. 13-27). Prace Naukowe Uniwersytetu Śląskiego.

SIWEK, T. (2005): Ethnic Identity vs. Declared Nationality in the Czech Part of Teschen Silesia (Zaolzie). In: Koter, M. and Hefner, K. [eds.]: The Role of Borderlands in United Europe: Historical, Ethnic and Geopolitical Problems of Borderlands. Region and Regionalism, 7(2): 115-122. Łódź, Opole, University of Łódź and Silesian Institute in Opole.
SIWEK, T. (2018): Silesian Identity across the Internal Border of the EU. In: Borders in Central Europe after the Schengen Agreement (pp. 167-177). Cham, Springer.

SLOCUM, T. A., MCMASTER, R. B., KESSLER, F. C., HOWARD, H. H. (2009): Thematic cartography and geovisualization, 3rd Edition, Pearson Prentice Hall.

STRASSOLDO-GRAFFENBERG, R. (1974): Friaul-Julisch Venetien als Europäische Aussenregion. Schriftenreibe des Instituts fur Staidtebau und Raurnordnung. Innsbruck.

SZCZYRBA, Z. (2005): Współpraca transgraniczna w układzie euroregionów na czesko-polskim pograniczu - możliwości rozwoju turystyki. Śląsk Opolski, 15(1-2): 58-64.

ŠIMON, M. (2015): Measuring phantom borders: the case of Czech/Czechoslovakian electoral geography. Erdkunde 69(2): 139-150.

TYKKYLÄINEN, M. (2009): Economies, Borderland. In: Kitchin, R., Thrift, N. [eds.]: International encyclopedia of human geography (pp. 345-353). Elsevier.

VAN HOUTUM, H. (1998): The development of cross-border economic relations. Tilburg, Tilburg University Press.

WARD JR, J. H. (1963): Hierarchical grouping to optimize an objective function. Journal of the American statistical association, 58(301): 236-244.

WOODCOCK, C. E., Gopal, S. (2000): Fuzzy set theory and thematic maps: accuracy assessment and area estimation. International Journal of Geographical Information Science, 14(2): 153-172.

\section{Please cite this article as:}

PÁSZTO, V., MACKU゚, K., BURIAN, J., PÁNEK, J., TUČEK, P. (2019): Capturing cross-border continuity: The case of the Czech-Polish borderland. Moravian Geographical Reports, 27(2): 122-138. Doi: 10.2478/mgr-2019-0010. 